\title{
Adoption of ICT enabled extension support system for vegetable crop production among small holder farmers: a case of Tanzania
}

\author{
Theofrida J. Maginga ${ }^{1 *}$ and Mussa Ally ${ }^{2}$ \\ Researcher, Sokoine University of Agriculture, Tanzania ${ }^{1}$ \\ Lecturer, Nelson Mandela African Institution of science and technology Arusha, Tanzania ${ }^{2}$
}

Received: 18-May-2019; Revised: 16-July-2019; Accepted: 18-July-2019

(C)2019 Theofrida J. Maginga and Mussa Ally. This is an open access article distributed under the Creative Commons Attribution (CC BY) License, which permits unrestricted use, distribution, and reproduction in any medium, provided the original work is properly cited.

\begin{abstract}
The study focuses on farmers adoption to ICT enabled systems for managing vegetable cropping activities. It ranges on how farmers use technological devices to the acquiring of information through extension support systems. A total of 150 small holder farmers of three regions from three main horticultural zones in Tanzania was randomly selected from vegetable crop farmers and 30 agronomists from different areas across the country. Data were collected through questionnaires and interviews and analyzed by tableau platform. In order to fulfill the focus described above. The findings depicted that a number of farmers had previous experience on the use technological devices but not so familiar with ICT enabled extension support systems for helping them to acquire data on best weather condition and requirements for their vegetable crop production, moreover small holder farmers and agronomist still believe that it's useful and beneficial for the implementation of ICT enabled extension support systems.
\end{abstract}

\section{Keywords}

ICT, Extension support system, Small holder farmer, Vegetable, Cropping system.

\section{Introduction}

\subsection{Background}

Information and communication technology in agriculture has been identified as the key dimension to agricultural sector growth all around the world, in response to that meanwhile the establishment for eagriculture community plays an important role in improving decision making, sharing knowledge, improving the livelihoods of the individuals by managing the crop management activities through building sustainable food security and agricultural practices [1].

Apart from ICT providing a fast way for interaction some of the mobile payment systems provide farmers with the ability to acquire information services that provides access to critical data such a weather data and disease outbreaks. Access to the timely and right information, gives farmers the ability to make well informed decisions that impact on their livelihood and ensures food security.

\footnotetext{
*Author for correspondence
}

ICT is currently being considered as a tool for change for small holder's farmers specifically for women. It brings out a huge profit for the agriculture value chain when rightly induced in day to day practices of agriculture [2].

According to [3] greater efficiencies in the use of diverse natural resources such as soil nutrients, water, fertilizers and energy has been enabled through the introduction of new information and communication technologies by using an information and knowledgebased approach rather than input intensive agriculture. Effective use and access timely information helps to improve, manage inputs, throughputs and outputs from crop activities, some of the initiated technologies have gone further on monitoring good agricultural practices, trace the farm products and manage pests and diseases.

In Tanzania, where horticulture is the mainstay of development with annual growth of $4.2 \%$ it contributes to at least three quarters of employment for Tanzanian workers, due to the growth of population in this area by more than a million people each year food security is significant [4]. Recent 
studies have focused on examining the importance of technology adaptation in agriculture for several households in Tanzania. Results have shown several constraints to the adoption of technology such as access to information and human capital [5].

\subsection{Theoretical study}

In Tanzania, extension services for agricultural practices are undertaken through the ministry of agriculture with the local procedures where it is free of charge, including services such as farm visits, organizing field days supported mostly by initiatives funded internationally with organization like USAID. Meanwhile, there are still a number of steps to be taken for improving the services since effectiveness and knowledge are very important factors in agricultural activities [4].

During previous times before the massive use of ICT for helping farmers in various agricultural activities extension services has always adapted to a linear model where information is being passed from the research institutions through extension officers and lastly to farmers [6]. In the years 1960s to 1970 s radio was used to deliver information to farmers.

Currently common methodologies used are training and visit approach which turned out to be working in some places, and also the face to face approach where it has been costly in terms of resources such as finances, logistics, skilled experts and not easily sustained. In that context most extension services have been about common practices not paving ways for farmers to solve complex issues faced in their farms instead the focus is only on the obvious practices such as high yielding, pest management, application of chemical fertilizers and pesticides of which in turn growth in agricultural activity became stagnant for most areas. The linear extension model has not been yet successful to support farmers in dealing with complex farm issues and so knowledgebased farming is a way through for farmers to be able to participate in a highly competitive market and global agricultural environment [1].

\section{Literature review}

Information and computer technology (ICT) are rapidly changing across the globe. Digital technologies that allow people to be interconnected and share the information are being adapted all over the world at high speed [7].
Globally ICT applications have been in abundance in the field of agriculture and from these applications, users can exchange information, agricultural experts and even policy makers. Raising awareness among the agricultural stakeholders has been the major impact of these ICT applications, to mention a few some of these applications include e-Agriculture Community of Practice run by the Food, Agriculture Organization, the ICT Observatory for Agricultural and Rural Cooperation, InfoDev all of these apps aims at sharing knowledge, build the capacity to farmers and also ensure high productivity and food security [8].

In agricultural practices were especially in Africa, small holder farmers who have been planting the same crops over a long period of time on the very same soil conditions and weather patterns change, faces diseases and pests that come and go [9]. Farmers need to acquire updated information that will allow them to cope with these changes and be able to benefit from them. The biggest challenge is on the provision of this information and such knowledge needs to tailored specifically as per distinct conditions due to agricultural localized nature [3].

In Africa, where agriculture is practiced in traditional ways by most of the small holder's farmers, this agricultural type is comprised with many challenges such as low yielding production, it is rain fed and lacks access to timely and critical information for market facilitation [10]. On such challenges if ICT gets to be embedded in stakeholder systems may help to bring growth and economic development and also bridge the knowledge gaps for better agricultural practices. Currently there is massive ownership of personal ICT devices such as mobile phones and Tablets among different individual of which it has brought an advantage to the application developers and meanwhile mobile technology is highly adopted as the number one choice of technology for delivering ICT solutions [11].

\section{Objectives}

The main focus of this paper is to

- Access the adaptability of the information and communication technologies used to manage the cropping activities for vegetable production.

- Analyzing the use of ICT devices by the small holder farmers in relation to the extension support system available used on vegetable cropping system. 


\section{Materials and methods}

\subsection{Study area}

The study conducted in Tanzania where there are millions of hectares of agriculture, only a small area is cultivated as per the agricultural sector development strategy from the fact that some of the area have land degradation, drought and low soil fertility. Up to now, in Tanzania agriculture has become more centered on land expansion of cultivation rather than focusing on high yield productivity.

\subsection{Data collection}

The data collection for the study included areas located in most horticultural productivity zones, the zones comprised of the areas which are Lake zone
(Mwanza), Coastal Zone (Dar es salaam, Coast and Morogoro) and Northern Zone (Kilimanjaro, Tanga, Manyara and Arusha) as shown on Figure 1 and so the regions for data collection were selected including Arusha, Mwanza and Morogoro. The main key respondents included farmers and extension officers; questionnaires were provided for primary data collection. The method gave a room for these respondents to give feedback on the experiences anonymously [12] the key informants also participated in the discussions, meanwhile agronomists were also being interviewed. Data collected through all these methods were analyzed by tableau platform.

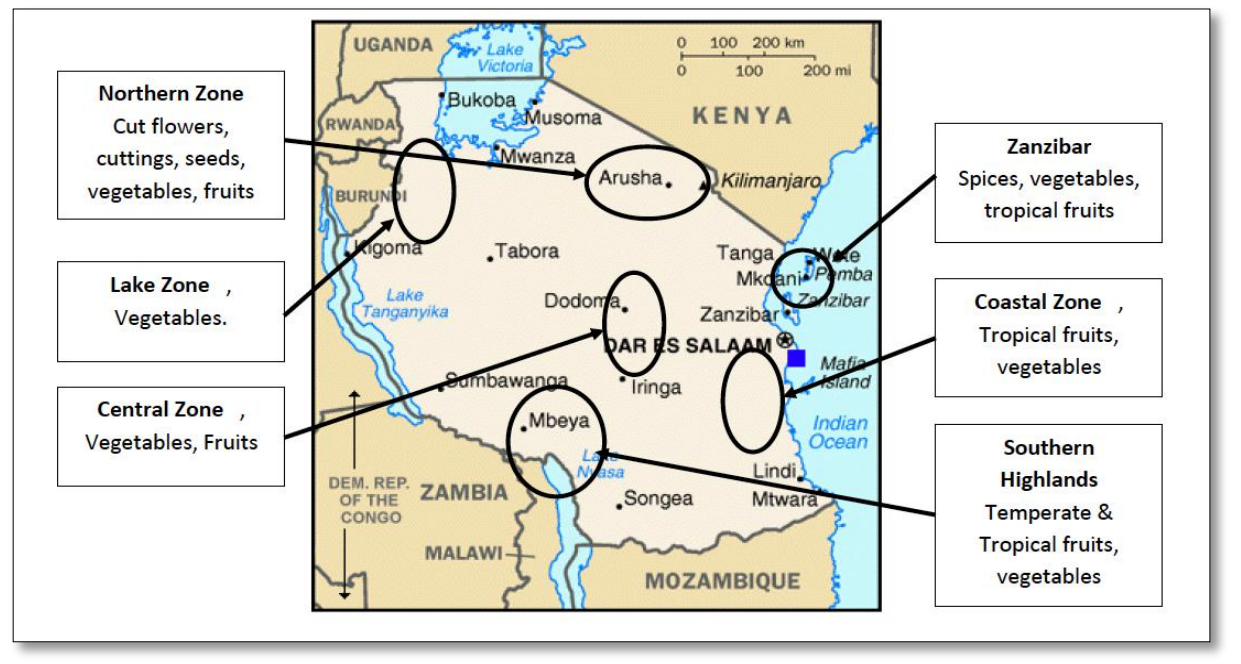

Figure 1 Tanzania map indicating main horticultural zone areas (Source: [4])

\section{Results}

The study has intended to capture the knowledge on what extent are the ICT devices being utilized for extensive support system to help small holder farmers in managing their vegetable cropping system. In this study, the primary aim of the researcher is to understand on how much technological devices are used by the small holder farmers. The study comprised of the 180 respondents selected from the area specified in the areas above, agronomists were 30 and small holder farmers who were as well being represented by the extension officers were 150 respondents. The survey, carried out had the focus on finding the number of small holder farmers that engages ICT for managing vegetable cropping system together with extension services into their day to day vegetable cropping system.
The survey criteria comprised of the followings gender, education backgrounds, types of vegetables grown in a particular area, use of technological devices and whether should the technological systems should be involved in vegetable cropping systems or not. The results acquired from the survey were analyzed through Tableau platform and presented as follows:

\subsection{Education background}

The results obtained on Figure 2 show that $79.73 \%$ of the 145 farmers engaged with vegetable crop production are female farmers. Out of all respondents, $65.52 \%$ are female farmers with primary education level. Male respondents make a total of $20.27 \%$. The large number of female farmers being engaged with vegetable cropping could more productively if these women were to be exposed on 
access to information. Based on the fact that women are not highly favored when it comes to extension resources. services there is a need for them to be empowered and be given high priority on knowledge-based

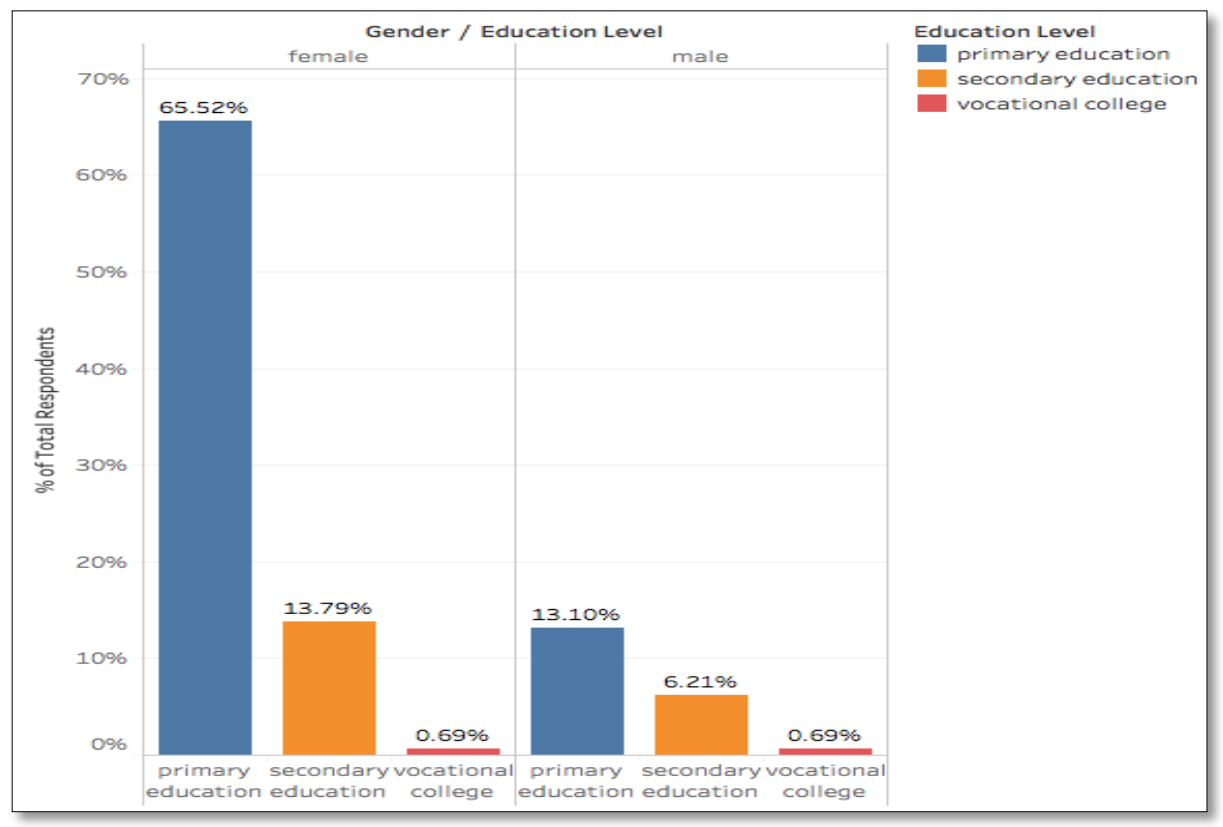

Figure 2 Educational background for female and male small holder farmers

\subsection{Vegetable crops production}

Each farmer responded to the types of the vegetable crops that they are dealing with. Most farmers were found to cultivate more than one type of vegetable crops. The consideration was on a major crop being cultivated by the particular farmer in relation to their education level, and results were obtained as shown on Figure 3.

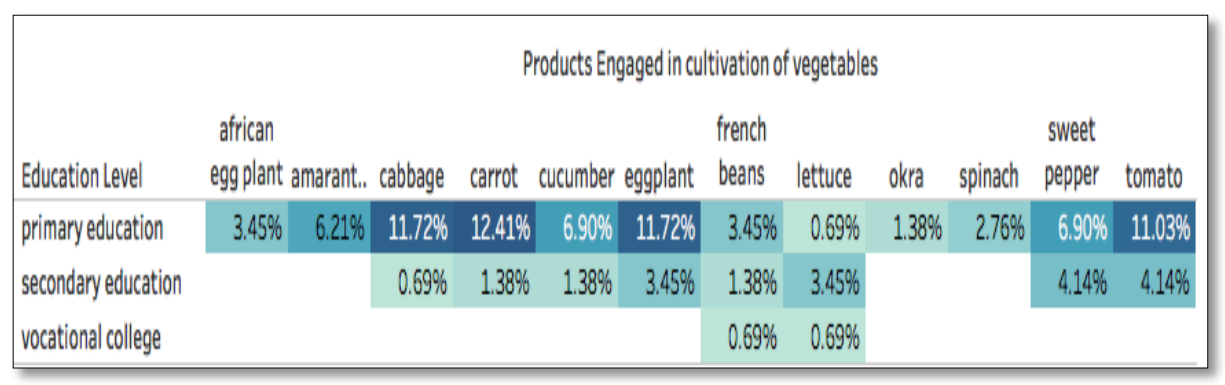

Figure 3 Types of vegetable crop cultivation with education background among small holder farmers

\subsection{Technology devices use}

The targeted technological devices in use by small holder farmers ranged from smart phones or any other related device made for communication. This part of the survey helped to understand the level of farmer engagement on the use technological devices. The following are the results of the responds with regards to the use of technology. 


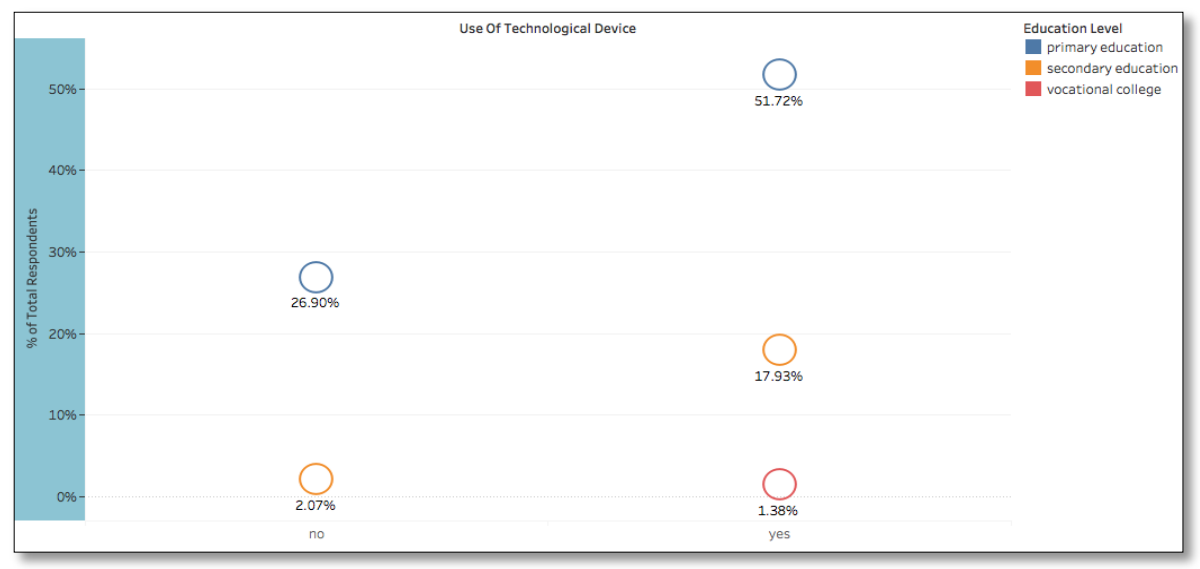

Figure 4 Use of technological devices for small holder farmers

The possession of technological devices was analyzed against educational backgrounds of the respondents as seen in Figure 4, in order to establish relations between the two. The results indicate that education level contributes to an impact on the use of technological devices for small holder farmers. Meanwhile, a reasonable percent, that is about $71.03 \%$ out of 145 respondents are technological device users.
Extension support system availability and development of technological extension support system. The results shown on Figure 5 explain the obtained data from through questionnaire, to give a depiction on extension support system(s) available for small holder farmers. A total of $78.71 \%$ out of 30 agronomists agreed that there are weaknesses on extension support systems available and the need for developing an ICT enabled extension support system.

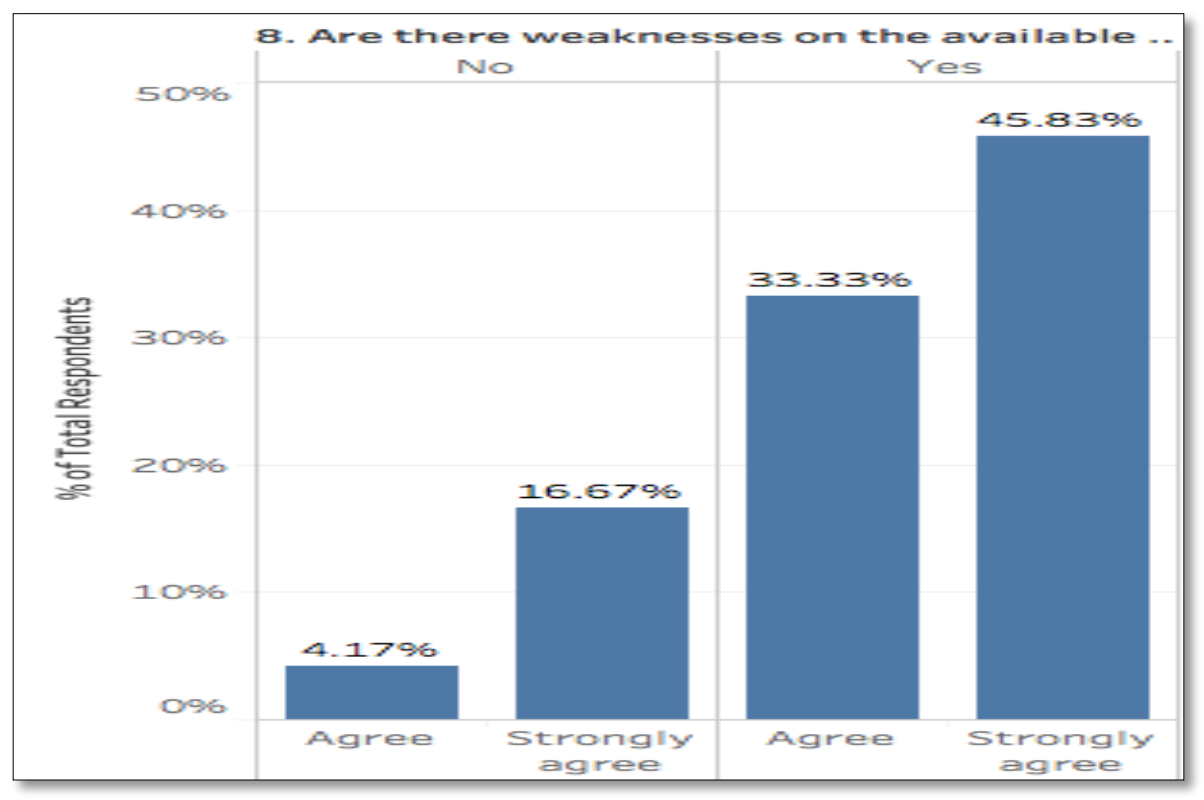

Figure 5 Available extension support system weaknesses

5.4Experience in the use of the available extension support system

Results on Figure 6 show respondents' experience of using the available technological extension support system. Out of 30 agronomists, $45.83 \%$ have experienced a great value and $45.83 \%$ of the users have nothing to say since they have not come across any of the technological extension support system. On a very few percentages, the agronomists have come across a poor value of the technological 
extension support system not meeting the required needs.

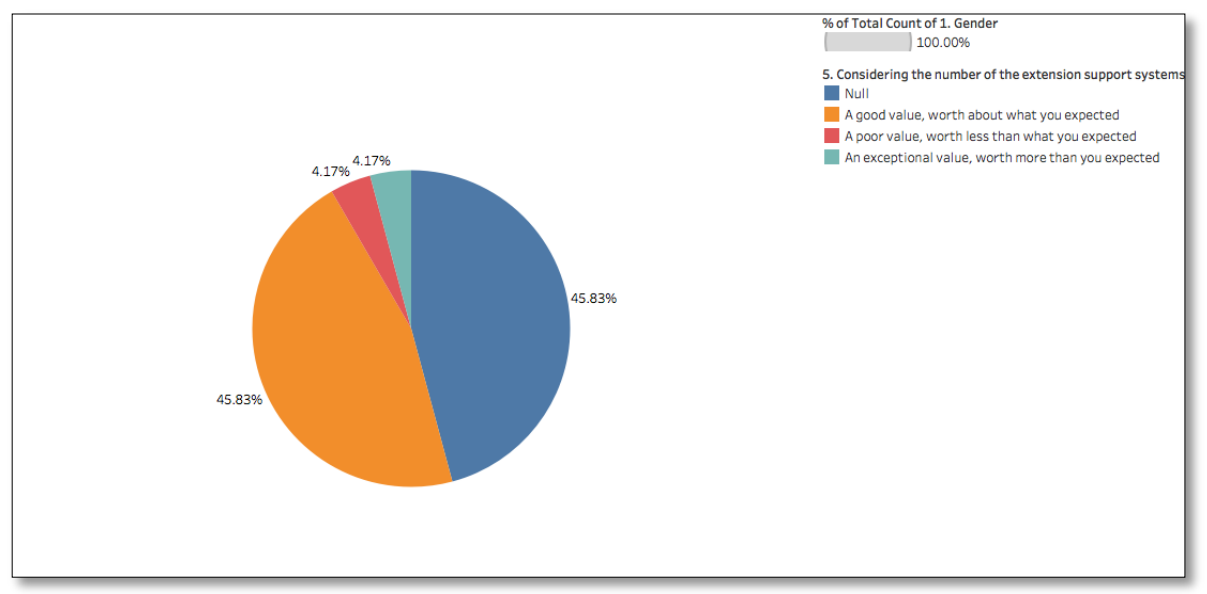

Figure 6 Experience for the agronomists on the use of available extension support system

\section{Discussion}

Furthermore, Pinthukas (2015) [13] argues that education level and trainings provided to the farmers have a very huge impact on enhancing knowledge of farming and vegetable crop production. The results shown on Figure 3 interprets that there are diversified types of vegetables being cultivated, but still few of them are cultivated more than others. It can be observed that a tomato is cultivated by $15.17 \%$, eggplant by $15.17 \%$, carrot by $13.79 \%$, cabbage $12.4 \%$ seem to be crops that are cultivated with farmers from all the education background. In the cases of crops such as French - beans and lettuce are barely cultivated all farmers as far as the educational background is concerned.

However, on Figure 4 results show that $26.90 \%$ out of $28.90 \%$ of the respondents are small holder farmers with primary education level not engaged with the technological device use, but this does not obstruct any proposed technological solution for the small holder farmers since the extension officers are educated and a large number of them can interact with technological devices.

\section{Proposed solution}

Extension support system development is being presented as a viable solution for small holder farmers, of which the system will cover weather stations by region in Tanzania with their particular information, on the platform that is going to a web application. The major key functions of the platform will include;

- Weather data, (temperature and precipitation) on the specified weather stations.

- Seven vegetable crops will be included with their respective requirement information.

- Information on possible pests and diseases that are likely to affect the vegetable crops.

- The user will have access to data on when is the best period to start cultivating their crops in their particular locations and the time to harvest those crops based on the weather data and the prediction given by the system.

- The system is going to provide the forum for farmers, extension officers and agricultural experts to interact. 


\section{Proposed framework}

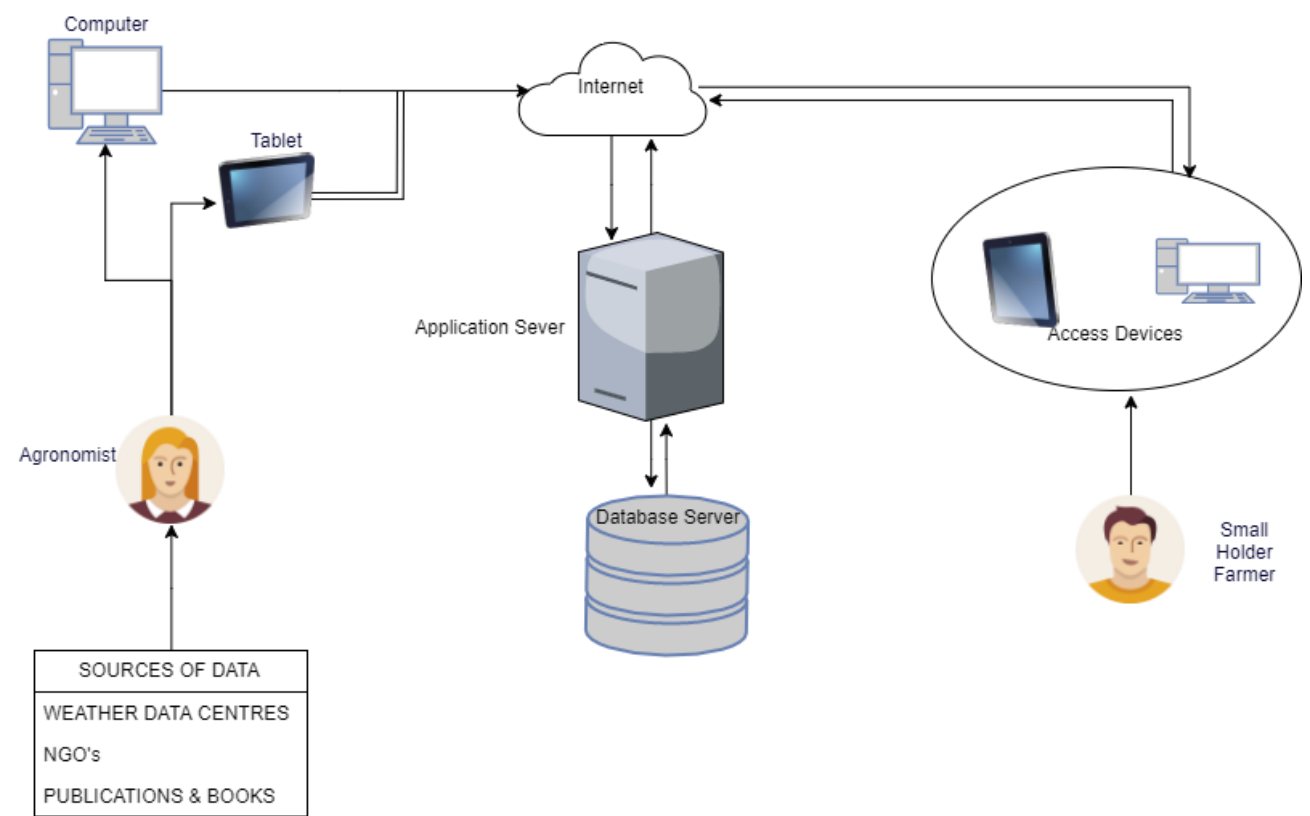

Figure 7 Extension support system framework

\section{Conclusion}

Results from the analyzed survey data depicted that the existence of ICT enabled extension support system for small holder farmers is quite not yet well adopted by the small holder farmers, extension officers and agronomists. The perception of small holder farmers who responded to the survey towards the use technological system for their vegetable cultivation activities is quite mixed, nevertheless both small holder farmers and agronomist still believe that it's useful and beneficial to adopt the ICT enabled extension support system. Meanwhile, for the few agronomists who have come across the few ICT enabled extension support system for farmers find that there is a need for adapting to more systems to help farmers manage their day to day vegetable cropping system.

Many of the small holder farmers have better common practices for managing their vegetable cropping system like using mixed cropping, irrigation system to obtain a proper yield. Yet there are few constraints such as proper information on how to plant based on weather data and best crop requirements for their vegetable needs to be adopted through ICT enabled extension support solution for better yielding.

\section{Acknowledgment}

This work is a part of the project supervised by The World Vegetable Centre AVRDC in Tanzania funded by CIRAD in France. However, this work has also been facilitated by The Nelson Mandela African Institute of Science and Technology under the African Development Bank sponsorship..

\section{Conflicts of interest}

The authors have no conflicts of interest to declare.

\section{References}

[1] Sylvester G. Information and communication technologies for sustainable agriculture-indicators from Asia and the Pacific. RAP Publication. 2013.

[2] Palmer N. Using ICT to enable agricultural innovation systems for smallholders ICT innovations.2012.

[3] McNamara K, Belden C, Kelly T, Pehu E, Donovan $\mathrm{K}$. Overview of ICT in agriculture: opportunities, access, and cross-cutting themes. ICT in Agriculture. 2011:1-4.

[4] https://www.rvo.nl/sites/default/files/2017/05/Tanzani a\%20Tuinbouwsecor\%20Overzicht.pdf. Accessed 16 March 2019.

[5] Kinuthia BK, Mabaya E. The impact of agricultural technology adoption on farmer welfare in Uganda and Tanzania. AFRICA PORTAL 2017.

[6] Spielman DJ. Innovation systems perspectives on developing-country agriculture: a critical review. IFPRI 2005.

[7] Janssen SJ, Porter CH, Moore AD, Athanasiadis IN, Foster I, Jones JW, et al. Towards a new generation of agricultural system data, models and knowledge 
products: information and communication technology. Agricultural Systems. 2017; 155:200-12.

[8] http://www.fao.org/3/a-i7961e.pdf. Accessed 16 March 2019.

[9] Nordey T, Basset-Mens C, De Bon H, Martin T, Déletré E, Simon S, et al. Protected cultivation of vegetable crops in sub-saharan Africa: limits and prospects for smallholders. a review. A gronomy for Sustainable Development. 2017; 37(53):1-20.

[10] Laureys F. Use of ICT for Agriculture in GIZ projects-Status quo, opportunities and challenges. Deutsche Gesellschaft für Internationale Zusammenarbeit (GIZ) GmbH. 2016.

[11] Zyl OV, Alexander T, Graaf LD, Mukherjee K. ICTs for agriculture in Africa World Bank, Washington, DC 2014.

[12] https://www.sheffield.ac.uk/lets/strategy/resources/eva luate/general/methods-collection/questionnaire. Accessed 16 April 2019.

[13] Pinthukas N. Farmers' perception and adaptation in organic vegetable production for sustainable livelihood in Chiang Mai province. Agriculture and Agricultural Science Procedia. 2015; 5:46-51.

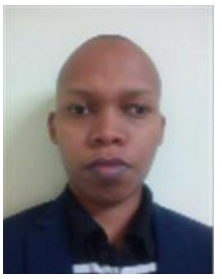

Dr. Mussa Ally Dida has been a Lecturer of NM-AIST since 2017 and an Academic manager of Centre of excellence for ICT in East Africa (CENIT@EA) also hosted by NMAIST. Before his promotion, he has previously he has been an Assistant Lecturer at NM-AIST from April 2012 to June 2017. He received his $\mathrm{PhD}$ in Communication Engineering at Beijing Institute of Technology in June 2017 and a Masters of Science in Telecommunication Engineering at University of Dodoma in 2011 and a Bachelor of Science in Computer engineering and Information Technology from university of dar Es Salaam in 2008. His research interests include Tanzania Digital Signal Processing, Physical Layer Security, and Embedded System for Agriculture.

Email: mussa.ally@nm-aist.ac.tz

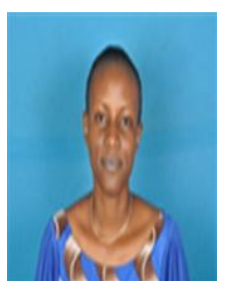

Miss. Theofrida J. Maginga is a Tutorial Assistant at Sokoine University of Agriculture in ICT area, she has received her Masters Degree in Information and Communication Science and Engineering at NM-AIST by April 2019. During her academic research which is titled as Development of horticultural extension support system for small holder farmer, she received a recognition certificate for an innovative research given by the NM-AIST for developing a tool that helps to predict the best sowing period for vegetable crops in Tanzania. She has also received a Bachelor degree in Information Technology at Stefano Moshi memorial University College at Kilimanjaro Tanzania in 2016. 